\title{
COMUNICAÇÃOCIENTÍFICA
}

\section{SELEÇÃO DE PORTA-ENXERTOS RESISTENTES AO CANCRO DA HASTE E SEUS EFEITOS NA PRODUTIVIDADE DE MELÃO 'BÔNUS N' 2'1}

\author{
LETÍCIAAKEMI ITO², HAMILTON CÉSAR DE OLIVEIRACHARLO ${ }^{3}$, \\ RENATACASTOLDI ${ }^{4}$, LEILA TREVIZAN BRAZ $^{5}$, MARGARETECAMARGO $^{6}$
}

RESUMO-A utilização de porta-enxertos resistentes a condições adversas é uma alternativa no controle de doenças, e a enxertia tem-se destacado no controle de patógenos habitantes de solo de diversas frutas e olerícolas. Diante disto, o presente trabalho teve por objetivos selecionar porta-enxertos resistentes ao cancro da haste e avaliar seus efeitos na produtividade de melão-rendilhado. Para a seleção de genótipos resistentes à Didymella bryoniae, foram utilizados 17 genótipos de cucurbitáceas. Dentre estes, apenas Melancia- Charleston-Gray e Melão-Redondo-Amarelo foram suscetíveis ao patógeno. Para efeitos da produtividade, foram enxertados sobre os genótipos resistentes, melão-rendilhado 'Bônus n ${ }^{\circ}$ '. O portaenxerto Benincasa hispida é o mais indicado para melão- rendilhado.

Termos para indexação: porta-enxerto, enxertia, Didymella bryoniae, Cucumis melo L.

\section{ROOTSTOCKS SELETION TO GRUMMY STEM BLIGHT RESISTANCE AND THEIR EFFECT ON THE YIELD OF MELON'BONUS ‘BONUS N’ 2’}

\begin{abstract}
The utilization of resistant rootstocks to adverse conditions is an alternative on disease control and the grafting has been detached on the soil pathogen inhabitant control of many fruits and vegetables. The objective of the present research was the selection of resistantes rootstocks to gummy stem blight and evaluates their effects on production of lancewok melon. For the selection of resistance genotypes to $D$. bryoniae, was utilized 17 cucurbits genotypes. Only the rootstocks: Watermelon Charleston Gray and Round Melon Yellow showed susceptible to the pathogen. For the production effects, was grafted under resistance genotypes, 'Bonus $\mathrm{n}^{\circ} 2$ '. The Benicia hispid rootstock is the most indicated to melon. Index terms: rootstock, grafting, Didymella bryoniae, Cucumis melo L.
\end{abstract}

Recomenda-se o cultivo do melão-rendilhado em ambiente protegido para o maior controle das condições ambientais, além de possibilitar a semeadura em várias épocas, proporcionando várias colheitas por ano (Brandão Filho \& Vasconcellos, 1998). O aumento do cultivo de melões-rendilhados neste ambiente aumentou a ocorrência de doenças, como o cancro da haste ou crestamento gomoso, causado pelo fungo Didymella bryoniae, uma doença de crescente importância (Tsutsumi, 1995).

Devido à ausência de fungicidas eficientes no controle e à inexistência de cultivares resistentes (Kimati et al., 1997), há a necessidade de novas alternativas para o controle de $D$. bryoniae. Uma delas é o uso de porta-enxertos tolerantes às condições adversas (Rizzo et al., 2000). A enxertia é muito efetiva para o controle de doenças causadas por patógenos habitantes do solo (Oda, 1995). Santos et al. (2003) relatam a necessidade de estudos sobre a reação dos porta-enxertos aos patógenos, a compatibilidade entre gêneros e espécies da mesma família envolvidos na combinação e na avaliação da produção.

O trabalho foi conduzido com o objetivo de selecionar porta-enxertos resistentes ao cancro da haste e avaliar o desempenho de melão-rendilhado 'Bônus $n^{\circ} 2$ ' enxertado nos porta-enxertos resistentes.

\footnotetext{
'(Trabalho 042-08). Recebido em: 19-02-2008. Aceito para publicação em: 13-01-2009.

${ }^{2}$ Enga Agr $^{\mathrm{a}}$., Mestranda em Agronomia, Depto. de Produção Vegetal, FCAV/UNESP- Via de Acesso Paulo Donato Castellane Km 05 s/n, CEP14870-000, Jaboticabal-SP, e-mail: leleakemi@yahoo.com.br

${ }^{3}$ Eng. Agr., M.Sc., Doutorando em Agronomia, Depto. de Produção Vegetal, FCAV/UNESP, Câmpus de Jaboticabal.

${ }^{4}$ Eng ${ }^{a}$ Agra., M.Sc., Doutoranda em Agronomia, Depto. de Produção Vegetal, FCAV/UNESP, Câmpus de Jaboticabal.

${ }^{5}$ Profa. Dra. - Depto. de Produção Vegetal, FCAV/UNESP, Câmpus de Jaboticabal.

${ }^{6}$ Profa. Dra - Depto. de Fitossanidade, FCAV/UNESP, Câmpus de Jaboticabal.
} 
Para a seleção de genótipos resistentes ao cancro da haste, foram testados os porta-enxertos Abóbora-Jacarezinho, Abóbora-Menina-Brasileira, Moranga-Exposição, Moranga- Coroa, AbóboraNova-Caravela, Abóbora-Squash, Mogango-SulMineiro, Abóbora-Mini- paulista e AbóboraGoianinha, Abobrinha-Italiana-Caserta Melhorada, Melancia-Charleston-Gray, Melão-Redondo-Gaúcho, Melão-Redondo-Amarelo, Pepino-Caipira HS - 221, Pepino-Caipira Rubi, Benincasa hispida e Bucha.

$\mathrm{O}$ isolado teve procedência da cultura do melão da cidade de Jaboticabal-SP. O patógeno foi cultivado em meio de aveia (MA). Foram retirados os discos contendo micélio ( $5 \mathrm{~mm}$ de diâmetro), para posterior inoculação através do método do palito, descrita por Verzignassi et al. (2004).

$\mathrm{O}$ delineamento experimental adotado foi o de blocos ao acaso, com 17 tratamentos e quatro repetições, mais testemunha. Os dados obtidos foram submetidos à análise de variância (teste F), e as médias, comparadas pelo teste de Tukey, a 5\% de probabilidade. Foram inoculadas quatro repetições de cada tratamento, representando cada repetição, em vaso com três plantas. Após a inoculação, as plantas foram mantidas em câmara úmida por 72 horas . Após este período, foram transferidas para casa de vegetação. A avaliação foi realizada após inoculação, utilizando-se de notas adaptadas por Dusi et al. (1994).

Com a finalidade de avaliar os efeitos da enxertia na produtividade de melão- rendilhado 'Bônus $\mathrm{n}^{\circ}$ 2', foram utilizados os porta-enxertos considerados resistentes na seleção. As plantas enxertadas para a avaliação da produtividade não foram inoculadas.

A enxertia realizada foi a garfagem do tipo fenda cheia. $O$ processo da enxertia foi executado 21 dias após a semeadura dos porta-enxertos. Foram realizadas 100 enxertias para cada tratamento. As mudas enxertadas foram submetidas a uma câmara com alta umidade até o seu pegamento. A taxa de pegamento foi determinada por meio da quantidade de enxertias que sobreviveram após 20 dias.

Vinte dias após a enxertia, realizou-se o transplante para a casa de vegetação, e as plantas foram tutoradas em fitilho. Foram realizadas podas semanais dos brotos.

Cada um dos 14 tratamentos foi avaliado com três repetições, sendo cada parcela constituída por 12 plantas. O delineamento utilizado foi o de blocos ao acaso, e a análise estatística foi realizada por meio da análise de variância (teste F), e as médias, comparadas pelo teste de Tukey, a 5\% de probabilidade.
Foram avaliados os diâmetros do caule a 1 $\mathrm{cm}$ acima, $1 \mathrm{~cm}$ abaixo e no local da enxertia quando as plantas estavam com dois metros de altura. Para a produtividade, foram avaliadas as características de produção total de frutos, diâmetros longitudinal e transversal do fruto, diâmetros longitudinal e transversal do lóculo, espessura da polpa e teor de sólidos solúveis de melão-rendilhado 'Bônus nº 2', enxertado em 12 porta-enxertos.

Na Tabela 1, são apresentadas as médias das notas atribuídas aos 10 dias após a inoculação. Apenas os porta-enxertos Melancia-CharlestonGray e Melão-Redondo- Amarelo foram suscetíveis ao cancro da haste, com as notas 3,00 e 2,33, respectivamente.

Os porta-enxertos: Bucha e Pepino-Caipira HS-221, ambos resistentes ao cancro da haste, não germinaram em quantidade suficiente para a realização das enxertias, e por isso não foram avaliados quanto à produtividade.

Apenas nas enxertias que utilizaram os portaenxertos Abobrinha-Italiana-Caserta Melhorada, Pepino-Caipira Rubi, Abóbora-Squash e AbóboraNova-Caravela, houve taxas de pegamento inferiores a $80 \%$. Nos demais porta-enxertos, as taxas de pegamento foram próximas a $100 \%$ (Figura 1).

As enxertias foram realizadas num dia muito quente, o que pode ter estressado as plantas enxertadas e causado a morte de algumas delas. $\mathrm{O}$ fato de terem sido utilizados diferentes genótipos de cucurbitáceas, como abóboras, morangas, pepinos, melões e melancia, que possuem características diferentes, assim como o crescimento e a fisiologia, pode também ter influenciado na taxa de pegamento das enxertias, já que os porta-enxertos foram semeados no mesmo dia, e o crescimento foi desigual, tendo as abóboras desenvolvimento mais acelerado quando comparados ao do melão e melancia. Os porta-enxertos de pepinos estiolaram em relação aos demais, o que dificultou o processo de enxertia e consequentemente interferiu negativamente na porcentagem de pegamento.

Estudos com relação ao momento ideal da realização da enxertia, assim como da semeadura de cada porta-enxerto utilizado e as condições climáticas ideais, são necessários com a finalidade de se minimizarem o estresse das plantas enxertadas e as perdas no processo.

Para o diâmetro do porta-enxerto a $1 \mathrm{~cm}$ abaixo do local de enxertia, o maior valor encontrado foi no porta-enxerto Abóbora-Moranga-Coroa, e o menor, no porta-enxerto Abóbora-Menina-Brasileira, com médias de 10,55 e 6,21, respectivamente (Tabela 2). 
No local da enxertia, o maior diâmetro foi encontrado no porta-enxerto Abóbora- Squash, e o menor, no porta-enxerto Melão-Redondo-Gaúcho. O maior diâmetro no local da enxertia na AbóboraSquash demonstra que a região da enxertia ficou mais resistente, uma vez que ocorreu maior proliferação de células. Nos porta-enxertos das abóboras Jacarezinho, Moranga-Exposição, Moranga-Coroa, Abóbora-Nova-Caravela, Abóbora- Squash e Mogango-Sul-Mineiro, os diâmetros não diferiram entre si, bem como entre Abóbora-Minipaulista, Abóbora-Goianinha, Benincasa hispida, Pepino-Caipira-Rubi, Abobrinha-Italiana-Caserta Melhorada e da testemunha 'Bônus n' 2'(Tabela 2).

Para o diâmetro do caule, a $1 \mathrm{~cm}$ acima do local da enxertia, não houve diferença significativa entre os porta-enxertos, ou seja, os diferentes portaenxertos não influenciaram nos diâmetros do enxerto 'Bônus n' 2' (Tabela 2), demonstrando que até aquela data o porta-enxerto não influenciou no desenvolvimento da caule do enxerto.

Quanto à produtividade, o melão Bônus $n^{\circ}$ 2, enxertado em Benincasa hispida, foi a combinação mais produtiva $\left(5,27 \mathrm{~kg} \cdot \mathrm{m}^{-2}\right)$, não diferindo dos enxertados em Melão-RedondoGaúcho $\left(3,75 \mathrm{~kg} \mathrm{~m}^{-2}\right)$, Abóbora-Goianinha $\left(3,48 \mathrm{~kg} \mathrm{~m}^{-2}\right) \mathrm{e}$ da testemunha 'Bônus n⿳亠丷厂 2' $\left(3,65 \mathrm{~kg} \mathrm{~m}^{-2}\right)$.

O melão enxertado no Pepino-Caipira Rubi, Abóbora-Menina-Brasileira e Mogango- SulMineiro apresentou as menores médias de produtividade, não diferindo dos enxertados em Abóbora-Jacarezinho, Abóbora-Nova-Caravela, Moranga-Coroa, Abóbora-Squash, MorangaExposição e Abóbora-Minipaulista (Tabela 3).

Quando comparada à produtividade do melão enxertado no porta-enxerto Benincasa hispida, deste experimento, com a produtividade de melão-rendilhado 'Bônus n' 2 ' obtida por Gusmão (2001) $\left(5,67 \mathrm{~kg} \mathrm{~m}^{-2}\right)$, nas mesmas condições ambientais deste experimento, os resultados assemelham-se. Segundo o mesmo autor, a produção comercial de frutos por unidade de área é um dos fatores que melhor refletem a viabilidade do cultivo de uma espécie, em condições específicas de cultivo. Segundo o mesmo autor, produtividades de melãorendilhado superiores a $30 \mathrm{t} \mathrm{ha}^{-1}$ são um valor superior à média obtida no Brasil. Neste experimento, Abóbora-Goianinha, Melão-Redondo-Gaúcho, Benincasa hispida e a testemunha apresentaram produtividade superior a $30 \mathrm{t} \mathrm{ha}^{-1}$.

Nas avaliações referentes aos diâmetros (cm) longitudinal e transversal do fruto, diâmetros (cm) longitudinal e transversal do lóculo, espessura da polpa do fruto $(\mathrm{cm})$ e teor de sólidos solúveis ( ${ }^{\circ}$ brix), não foram detectadas diferenças significativas (Tabela 3). Para todas as características acima citadas, exceto teor de sólidos solúveis, os valores observados foram superiores aos resultados obtidos por Pádua (2001), com o melão-rendilhado 'Bônus n' 2' avaliado em condições semelhantes.

Com relação ao teor de sólidos solúveis, os resultados deste experimento estão entre os valores médios para melão-rendilhado 'Bônus no 2' (Pádua, 2001; Gusmão, 2001), superiores a 9 ºrix, valor mínimo exigido pelas normas de padronização de frutos para exportação (Gayet, 1994).

Embora não tenha sido uma característica de avaliação, observou-se que alguns frutos apresentaram a polpa de cor alaranjada com maior frequência entre os frutos colhidos nas parcelas com os porta-enxertos Moranga Exposição, Abóbora Goianinha e Melão-Redondo- Gaúcho. O melãorendilhado 'Bônus $\mathrm{n}^{\mathbf{0}} 2$ ' tem a característica de cor verde da polpa. Tal característica pode ter sido influenciada pelo porta-enxerto, portanto há a necessidade de estudos complementares.

As poucas plantas que sobreviveram na casa de vegetação do tratamento com o porta-enxerto Abobrinha-Italiana-Caserta Melhorada não produziram frutos comerciais, por este motivo não foram apresentados os resultados de produção e as características dos frutos deste tratamento.

O trabalho permitiu concluir que o portaenxerto Benincasa hispida é o mais indicado como porta-enxerto para melão-rendilhado. 
TABELA 1- Médias das notas atribuídas aos sintomas de cancro da haste, nos porta-enxertos, aos 10 dias após a inoculação com Didymella bryoniae. UNESP-FCAV, Jaboticabal - SP, 2006.

\begin{tabular}{lcc}
\hline Genótipos & Notas & Notas $^{2}$ \\
\hline Abóbora-Jacarezinho & 0,00 & $1,00 \mathrm{~b}^{3}$ \\
Abóbora-Menina-Brasileira & 0,00 & $1,00 \mathrm{~b}$ \\
Moranga-Exposição & 0,00 & $1,00 \mathrm{~b}$ \\
Moranga-Coroa & 0,00 & $1,00 \mathrm{~b}$ \\
Abóbora-Nova-Caravela & 0,00 & $1,00 \mathrm{~b}$ \\
Abóbora-Squash & 0,00 & $1,00 \mathrm{~b}$ \\
Morango-Sul-Mineiro & 0,00 & $1,00 \mathrm{~b}$ \\
Abóbora-Minipaulista & 0,00 & $1,00 \mathrm{~b}$ \\
Abóbora-Goianinha & 0,00 & $1,00 \mathrm{~b}$ \\
Benincasa hispida & 0,00 & $1,00 \mathrm{~b}$ \\
Bucha & 0,00 & $1,00 \mathrm{~b}$ \\
Abobrinha-Italiana-Caserta Melhorada & 0,58 & $1,24 \mathrm{~b}$ \\
Melancia-Charleston-Gray & 3,00 & $2,00 \mathrm{a}$ \\
Melão-Redondo-Gaúcho & 0,67 & $1,26 \mathrm{~b}$ \\
Melão-Redondo-Amarelo & 2,33 & $1,80 \mathrm{a}$ \\
Pepino-Caipira HS - 221 & 0,75 & $1,30 \mathrm{~b}$ \\
Pepino-Caipira Rubi & 0,67 & $1,26 \mathrm{~b}$ \\
\hline CV (\%) & & 14,04 \\
\hline DMS (Tukey, 5\%) & & 0,4237 \\
\hline
\end{tabular}

${ }^{1}$ NOTAS: 0 - ausência de sintomas visíveis; 1 - lesão encharcada na haste da planta até $1 \mathrm{~cm}$ de diâmetro; 2 - lesão encharcada na haste da planta com mais de $1 \mathrm{~cm}$ de diâmetro; 3 - lesão parcialmente necrosada na haste com murcha parcial da planta; e 4 - necrose da haste com murcha total e morte da planta;

${ }^{2}$ Médias transformadas em $\sqrt{x+1}$;

${ }^{3}$ Médias seguidas pela mesma letra, na coluna, não diferem significativamente, ao nível de 5\% de probabilidade, pelo teste de Tukey.

TABELA 2- Médias (mm) dos diâmetros do caule a $1 \mathrm{~cm}$ acima, $1 \mathrm{~cm}$ abaixo e no local da realização das enxertias, de plantas de melão-rendilhado 'Bônus no ${ }^{2}$ ', no máximo de seu crescimento ( $2 \mathrm{~m}$ de altura), em diferentes porta-enxertos de cucurbitáceas. UNESP-FCAV, Jaboticabal - SP, 2006.

\begin{tabular}{lccc}
\hline Porta-enxertos & $1 \mathrm{~cm}$ abaixo & local $^{1}$ & $1 \mathrm{~cm} \mathrm{acima}^{1}$ \\
\hline Abóbora-Jacarezinho & $8,04 \mathrm{abcd}$ & $18,09 \mathrm{ab}$ & $9,70 \mathrm{a}$ \\
Abóbora-Menina-Brasileira & $6,21 \mathrm{~d}$ & $12,91 \mathrm{bc}$ & $8,53 \mathrm{a}$ \\
Moranga-Exposição & $8,80 \mathrm{abcd}$ & $17,32 \mathrm{ab}$ & $10,32 \mathrm{a}$ \\
Moranga-Coroa & $10,55 \mathrm{a}$ & $17,78 \mathrm{ab}$ & $9,72 \mathrm{a}$ \\
Abóbora-Nova-Caravela & $9,10 \mathrm{abc}$ & $17,99 \mathrm{ab}$ & $10,96 \mathrm{a}$ \\
Abóbora-Squash & $7,67 \mathrm{bcd}$ & $19,27 \mathrm{a}$ & $11,06 \mathrm{a}$ \\
Morango-Sul-Mineiro & $7,41 \mathrm{~cd}$ & $16,06 \mathrm{ab}$ & $10,76 \mathrm{a}$ \\
Abóbora-Minipaulista & $7,47 \mathrm{~cd}$ & $15,44 \mathrm{abc}$ & $9,54 \mathrm{a}$ \\
Abóbora-Goianinha & $7,54 \mathrm{~cd}$ & $15,46 \mathrm{abc}$ & $9,90 \mathrm{a}$ \\
Benincasa hispida & $10,36 \mathrm{ab}$ & $15,69 \mathrm{abc}$ & $9,94 \mathrm{a}$ \\
Pepino-Caipira Rubi & $9,65 \mathrm{abc}$ & $13,78 \mathrm{abc}$ & $9,23 \mathrm{a}$ \\
Abobrinha-Italiana-Caserta Melhorada & $7,20 \mathrm{~cd}$ & $15,55 \mathrm{abc}$ & $9,73 \mathrm{a}$ \\
Melão-Redondo-Gaúcho & $8,85 \mathrm{abcd}$ & $10,31 \mathrm{c}$ & $9,02 \mathrm{a}$ \\
Bônus n 2 (testemunha) & & $13,80 \mathrm{abc}$ & 9,94 \\
CV (\%) & 11,09 & 11,97 & 2,9348 \\
DMS (Tukey, 5\%) & 2,7781 & 5,6433 & \\
\hline
\end{tabular}

${ }^{1}$ Médias seguidas pela mesma letra, na coluna, não diferem significativamente, ao nível de $5 \%$ de probabilidade, pelo teste de Tukey. 
TABELA 3- Médias da produção total de frutos (PTF), diâmetro longitudinal do fruto (DL), diâmetro transversal do fruto (DT), diâmetro longitudinal do lóculo (DLL), diâmetro transversal do lóculo (DTL), espessura da polpa (EP) e teor de sólidos solúveis (SS) de frutos de melãorendilhado 'Bônus n 2', enxertado em 12 porta-enxertos, e do pé-franco (Bônus nº 2'). UNESPFCAV, Jaboticabal - SP, 2007.

\begin{tabular}{|c|c|c|c|c|c|c|c|}
\hline Porta-enxertos & $\mathrm{PTF}^{1}$ & $\mathrm{DL}^{1}$ & $\mathrm{DT}^{1}$ & DLL $^{1}$ & DTL $^{1}$ & $\mathrm{EP}^{1}$ & $\mathrm{SS}^{1}$ \\
\hline & $\left(\mathrm{kg} \cdot \mathrm{m}^{-2}\right)$ & $(\mathrm{cm})$ & $(\mathrm{cm})$ & $(\mathrm{cm})$ & $(\mathrm{cm})$ & $(\mathrm{cm})$ & ( brix) \\
\hline Abóbora-Jacarezinho & $2,48 \mathrm{bc}$ & $11,71 \mathrm{a}$ & $12,06 \mathrm{a}$ & $6,33 a$ & $5,56 \mathrm{a}$ & $3,22 \mathrm{a}$ & $8,52 \mathrm{a}$ \\
\hline Ab.-Menina-Brasileira & $1,13 \mathrm{c}$ & $10,82 \mathrm{a}$ & $11,42 \mathrm{a}$ & $5,41 \mathrm{a}$ & $5,36 \mathrm{a}$ & $3,01 \mathrm{a}$ & $9,79 \mathrm{a}$ \\
\hline Moranga-Exposição & $1,92 \mathrm{bc}$ & $10,77 \mathrm{a}$ & $11,35 \mathrm{a}$ & $6,80 \mathrm{a}$ & $5,36 \mathrm{a}$ & $2,93 \mathrm{a}$ & $7,92 \mathrm{a}$ \\
\hline Moranga-Coroa & $1,98 \mathrm{bc}$ & $11,47 \mathrm{a}$ & $12,10 \mathrm{a}$ & $6,82 \mathrm{a}$ & $5,65 \mathrm{a}$ & $3,20 \mathrm{a}$ & $8,72 \mathrm{a}$ \\
\hline Abóbora-Nova-Caravela & $2,27 \mathrm{bc}$ & $11,43 \mathrm{a}$ & $11,78 \mathrm{a}$ & $6,40 \mathrm{a}$ & $5,54 \mathrm{a}$ & $2,93 \mathrm{a}$ & $7,98 \mathrm{a}$ \\
\hline Abóbora-Squash & $1,98 \mathrm{bc}$ & $11,11 \mathrm{a}$ & $11,54 \mathrm{a}$ & $6,29 \mathrm{a}$ & $5,36 \mathrm{a}$ & $8,15 \mathrm{a}$ & $8,49 \mathrm{a}$ \\
\hline Morango-Sul-Mineiro & $0,92 \mathrm{c}$ & $11,48 \mathrm{a}$ & $11,96 \mathrm{a}$ & $6,61 \mathrm{a}$ & $5,25 \mathrm{a}$ & $3,21 \mathrm{a}$ & $9,92 \mathrm{a}$ \\
\hline Abóbora-Minipaulista & $1,83 \mathrm{bc}$ & $11,39 \mathrm{a}$ & $11,97 \mathrm{a}$ & $6,74 \mathrm{a}$ & $5,58 \mathrm{a}$ & $3,33 \mathrm{a}$ & $10,29 \mathrm{a}$ \\
\hline Abóbora-Goianinha & $3,48 \mathrm{ab}$ & $12,26 \mathrm{a}$ & $11,56 \mathrm{a}$ & $7,07 \mathrm{a}$ & $5,20 \mathrm{a}$ & $3,04 \mathrm{a}$ & $9,20 \mathrm{a}$ \\
\hline Benincasa hispida & $5,27 \mathrm{a}$ & $12,01 \mathrm{a}$ & $12,38 \mathrm{a}$ & $6,22 \mathrm{a}$ & $5,27 \mathrm{a}$ & $3,33 \mathrm{a}$ & $9,32 \mathrm{a}$ \\
\hline Pepino-Caipira-Rubi & $1,16 \mathrm{c}$ & $10,72 \mathrm{a}$ & $11,17 \mathrm{a}$ & $6,69 \mathrm{a}$ & $5,40 \mathrm{a}$ & $2,85 \mathrm{a}$ & $8,59 \mathrm{a}$ \\
\hline Melão-Redondo-Gaúcho & $3,75 \mathrm{ab}$ & $11,21 \mathrm{a}$ & $11,17 \mathrm{a}$ & $6,83 \mathrm{a}$ & $5,14 \mathrm{a}$ & $3,00 \mathrm{a}$ & $8,29 \mathrm{a}$ \\
\hline Bônus n² (testemunha) & $3,65 \mathrm{ab}$ & $11,81 \mathrm{a}$ & $11,48 \mathrm{a}$ & $6,99 \mathrm{a}$ & $4,67 \mathrm{a}$ & $3,31 \mathrm{a}$ & $8,98 \mathrm{a}$ \\
\hline Teste F & $8,54^{* *}$ & $1,90^{\mathrm{NS}}$ & $1,25^{\mathrm{NS}}$ & $1,82^{\mathrm{NS}}$ & $1,15^{\mathrm{NS}}$ & $1,19^{\mathrm{NS}}$ & $1,48^{\mathrm{NS}}$ \\
\hline $\mathrm{CV}(\%)$ & 30,48 & 5,24 & 5,04 & 8,57 & 7,65 & 8,38 & 11,85 \\
\hline
\end{tabular}

${ }^{1}$ Médias seguidas pela mesma letra, na coluna, não diferem significativamente, ao nível de $5 \%$ de probabilidade, pelo teste de Tukey.

** Significativo ao nível de $1 \%$ de probabilidade.

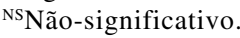

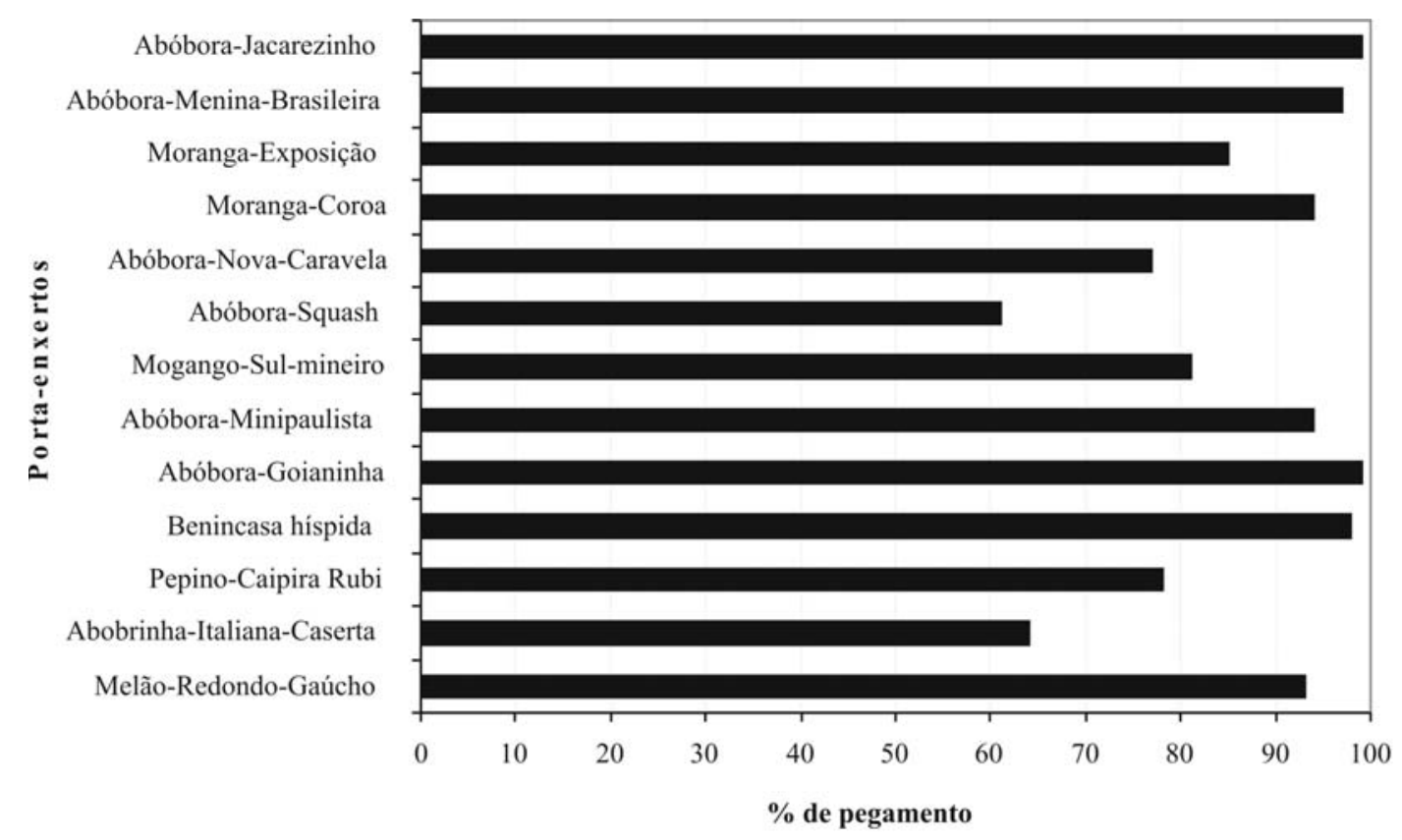

FIGURA 1- Porcentagem de pegamento, após 20 dias da realização das enxertias, de 13 porta-enxertos de cucurbitáceas, com melão-rendilhado ('Bônus n’ 2'). 


\section{AGRADECIMENTOS}

À FAPESP, pela concessão de bolsa de Iniciação científica à primeira autora do trabalho (Processo $n^{\circ}$ 05/58715-9) e pelo auxílio financeiro ao projeto (Processo n ${ }^{\circ}$ 05/59084-2).

\section{REFERÊNCIAS}

BRANDÃO FILHO, J. U. T.; VASCONCELLOS, M. A. S. A cultura do meloeiro. In: GOTO, R.; TIVELLI, S. W. Produção de hortaliças em ambiente protegido: condições subtropicais. São Paulo: Fundação Editora UNESP, 1998. p.161-194.

DUSI, A. N.; TASAKI, S.; VIEIRA, S. V. Metodologia para avaliação de resistência à Didymella bryoniae em melão. Horticultura Brasileira, Brasilia, v.12, n.1, p.43-44, 1994.

GAYET, J. P. Características das frutas de exportação. In: GORGATTI NETTO, A.; GAYET, J. P.; BLEINROTH, E. W.; MATALLO, M.; GARCIA, E. E.C.; GARCIA,A. E.; ARDITO, E.F. G.; BORDIN, M. R. Melão para exportação: procedimentos de colheita e pós-colheita. Brasília: FRUPEX, EMBRAPA, 1994. p. 9-10. (Publicações Técnicas, 6).

GUSMÃO, S. A. L. Interação genótipo x ambiente em híbridos de melão rendilhado (Cucumis melo var. reticulatus Naud.). 2001, 143f. Tese (Doutorado em Agronomia- Área de concentração em Produção Vegetal) - Faculdade de Ciências Agrárias e Veterinárias, Universidade Estadual Paulista. Jaboticabal, 2001.
KIMATI, H.; AMORIM, L.; BERGAMIN FILHO, A.; CAMARGO, L. E. A.; REZENDE, J. A. M. Manual de fitopatologia: doenças de plantas cultivadas. São Paulo: Ceres, 1997, p.331-332.

ODA, M. New grafting methods for fruit-bearing vegetables in Japan. Japan Agricultural Research Quarterly, Ohwashi, v.29, n.3, p.187-94, 1995.

PÁDUA, J. G. Cultivo protegido de melão-rendilhado, em duas épocas de cultivo. 2001, 108 f. Tese (Doutorado em Agronomia- Área de concentração em Produção Vegetal) - Faculdade de Ciências Agrárias e Veterinárias, Universidade Estadual Paulista, Jaboticabal, 2001.

RIZZO, A. A. N.; CHAVES, F. C. M.;LAURA, V. S.; GOTO, R. Avaliação de tipos de enxertia e portaenxertos para melão-rendilhado. Horticultura Brasileira, Brasília, v.18. n.1, p.466, 2000.

SANTOS, H. S.; GOTO, R.; KOBORI, R. F. In: RUMY, G.; SANTOS, H. S.; CAÑIZARES, K. A. L. Enxertia em hortaliças. São Paulo: Editora UNESP, 2003. p.19.

TSUTSUMI, C. Y. Triagem de populações de melão(Cucumis melo L.) para resistência à Didymella bryoniae(Auersw.) Rehm., 1995, 79 f. Dissertação (Mestrado em Agronomia- Área de concentração- Horticultura) - Faculdade de Ciências Agronômicas, Universidade Estadual Paulista, Botucatu, 1995.

VERZIGNASSI, J. R.; VIDA, J. B.; GASPAROTTO, F.; CORTEZ, G. L. S.; LORENZETTI, E. R.; FARIA, G. S. F.; TESSMANN, D. J.; SEVERINO, J. J. Método do palito para inoculação de Didymella bryoniae em melão-nobre e pepino-“japonês". Fitopatologia Brasileira, Brasília, v.29, p.154, 2004. Suplemento 